Journal of Computer Science 5 (12): 980-987, 2009

ISSN 1549-3636

(C) 2009 Science Publications

\title{
Optimal Thyristor Control Series Capacitor Neuro-Controller for Damping Oscillations
}

\author{
N. Magaji and M.W. Mustafa \\ Department of Power System, Faculty of Electrical Engineering, \\ University Technology Malaysia, 81310, Skudai, Malaysia
}

\begin{abstract}
This study applies a neural-network-based optimal TCSC controller for damping oscillations. Optimal neural network controller is related to model-reference adaptive control, the network controller is developed based on the recursive "pseudo-linear regression". Problem statement: The optimal NN controller is designed to damp out the low frequency local and inter-area oscillations of the large power system. Approach: Two multilayer-perceptron neural networks are used in the design-the identifier/model network to identify the dynamics of the power system and the controller network to provide optimal damping. By applying this controller to the TCSC devices the damping of inter-area modes of oscillations in a multi-machine power system will be handled properly. Results: The effectiveness of the proposed optimal controller is demonstrated on two power system problems. The first case involves TCSC supplementary damping control, which is used to provide a comprehensive evaluation of the learning control performance. The second case aims at addressing a complex system to provide a very good solution to oscillation damping control problem in the Southern Malaysian Peninsular Power Grid. Conclusion: Finally, several fault and load disturbance simulation results are presented to stress the effectiveness of the proposed TCSC controller in a multi-machine power system and show that the proposed intelligent controls improve the dynamic performance of the TCSC devices and the associated power network.
\end{abstract}

Key words: TCSC, neural network, power system oscillations, linear models, NARMA and MLP

\section{INTRODUCTION}

The concept of Flexible Ac Transmission Systems (FACTS) is made possible by the application of high power electronic devices for power flow and voltage control FACTS are being increasingly used to better utilize the capacity of existing transmission systems and is a technology based solution to help the utility industry deal with changes in the power delivery business. A major thrust of FACTS technology is the development of power electric based systems that provide dynamic control of the power transfer parameters transmission voltage, line impedance and phase angle ${ }^{[1,2]}$.

Power system oscillations occur due to the lack of damping torque at the generators rotors. The oscillation of the generators rotors cause the oscillation of other power system variables (bus voltage, bus frequency, transmission lines active and reactive powers). Power system oscillations are usually in the range between 0.1 and $2 \mathrm{~Hz}$ depending on the number of generators involved in ${ }^{[3,4]}$. Local oscillations lie in the upper part of that range and consist of the oscillation of a single generator or a group of generators against the rest of the system. In contrast, inter-area oscillations are in the lower part of the frequency range and comprise the oscillations among groups of generators.

To improve the damping of oscillations in power system, a Power System Stabilizers (PSSs) applied on selected generators can effectively damp local oscillation modes while for interarea oscillations a supplementary controller can be applied to TCSC devices. Most of these controllers are designed base on conventional approach that is designed based on a Linearized model which cannot provide satisfactory performance over a wide range of operation points and under large disturbances ${ }^{[5]}$.

Neural networks, enjoy a variety of advantages (e.g., high speed, generalization capability and learning ability), are a viable choice for non-linear control design. They have been successfully applied to the identification and control of dynamical systems especially in the field of adaptive control by making use of on-line training ${ }^{[6,7]}$.

Direct and indirect adaptive control with MLP and RBF neural networks has been discussed in ${ }^{[8,9]}$ for such

Corresponding Author: N. Magaji, Department of Power System, Faculty of Electrical Engineering,

University Technology Malaysia, 81310, Skudai, Malaysia 
systems which relies on continuous online training of the identifier and controller network.

The research on the application of neural networks to the FACTS controllers design so far includes online tuning of FACTS controller parameters ${ }^{[10-12]}$, the implementation of indirect adaptive and direct adaptive control FACTS controller in ${ }^{[12-14]}$.

Jung-Wook et al. ${ }^{[15]}$ Designed a supervised Neural network Controller base on Proportional-Integral (PI) controller for series TCSC device using Dual Heuristic Programming (DHP) optimization approach. The performance of the PI based conventional internal controller (CONVC) is compared with that of the DHP controller with respect to damping low frequency oscillations. This method, however need to have three different neural network model, model of Identifier, model of DHP controller and critic. In addition there are too many functions to store and training is base on offline unlike MLP that is straightforward to implement.

Dash et al. ${ }^{[16]}$ Presents single-neuron and multineuron Radial Basis Function Controller (RBFNN) for the UPFC control in single machine-infinite-bus and three-machine power systems and claimed to provide the best transient stability performance of the power system. This is because output layer of RBF can be optimized fully using traditional linear modeling techniques but, before linear optimization can be applied to the output layer of an RBF network, the number of radial units must be decided and then their centers and deviations must be set. Although faster than MLP training, the algorithms to do this are equally prone to discover sub-optimal combinations. RBF's requires a lot of units to adequately model most functions. Another drawback of RBF solution is will tend to be slower to execute and more space consuming than the corresponding MLP.

In this study, on-line trained neural networks are employed to design an adaptive neural network TCSC controller for a multi-machine power system. The proposed neural network TCSC controller design is started by designing a dynamic neuroidentifier for the TCSC device incorporated in a multimachine power system; then designing a neurocontroller for the TCSC device using the MLP network and train using Modified Recursive Prediction Error Algorithm (MRPEA). Finally compare the performance of the optimal neurocontroller with the conventional state feedback controller for a number of operating conditions.

\section{MATERIALS AND METHODS}

TCSC model: A typical TCSC module consists of a Fixed series Capacitor (FC) in parallel with a Thyristor
Controlled Reactor (TCR) as shown in Fig. 1. The TCR is formed by a reactor in series with a bi-directional thyristor valve that is fired with an angle ranging between 90 and $180^{\circ}$ with respect to the capacitor voltage ${ }^{[14]}$.

Consider a line 1 , having line reactance $X_{L}$, connected between buses $\mathrm{k}$ and $\mathrm{m}$. If the reactance of TCSC placed in the line 1 is $\mathrm{Xc}$, the percentage of compensation of TCSC $(\mathrm{kc})$ is given by:

$\mathrm{kc}=\frac{\mathrm{X}_{\mathrm{C}}}{\mathrm{X}_{\mathrm{L}}}$

The line power flows are functions of the degree of compensation of the TCSC. The real power $\left(\mathrm{P}_{\mathrm{km}}\right)$ and reactive power $\left(\mathrm{Q}_{\mathrm{km}}\right)$ in a line 1 (connected between buses $\mathrm{k}$ and $\mathrm{m}$ ), with TCSC having degree of compensation $\mathrm{k}_{\mathrm{c}}$ and neglecting the line resistance, can be written as:

$$
\begin{aligned}
& P_{k m}=V_{k} V_{m} B\left(x_{c}\right) \sin \left(\theta_{k}-\theta_{m}\right) \\
& P_{m k}=-P_{k m} \\
& Q k m=V_{k}^{2}\left(Y_{k m}+B\right)-V_{k} V_{m}\left(Y_{k m}+B\right) \cos \left(\theta_{k}-\theta_{m}\right) \\
& Q m k=V_{m}^{2}\left(Y_{k m}+B\right)-V_{k} V_{m}\left(Y_{k m}+B\right) \cos \left(\theta_{k}-\theta_{m}\right)
\end{aligned}
$$

The equivalent substance of the TCSC, is given by:

$\mathrm{B}(\mathrm{xc})=-\frac{\mathrm{x}_{\mathrm{C}} / \mathrm{x}_{1}}{\mathrm{x}_{1}\left(1-\mathrm{x}_{\mathrm{C}} / \mathrm{x}_{1}\right)}=\frac{\mathrm{k}_{\mathrm{C}}}{\left(\mathrm{k}_{\mathrm{C}}-1\right)} \mathrm{B}_{\mathrm{km}}$

The TCSC reactance is varied by varying the real power error $\left(\mathrm{P}_{\text {ref }}-\mathrm{P}\right)$.

Optimal adaptive neuro controller design: For engineering purposes, the neural network can be thought of as a black box model which accepts inputs, processes them and produces outputs according to some nonlinear transfer function ${ }^{[17]}$.

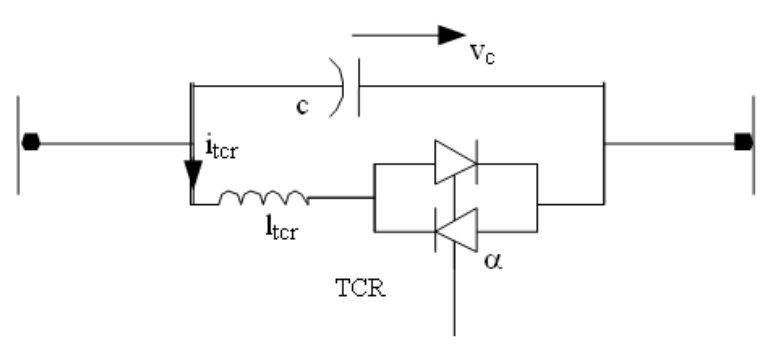

Fig. 1: TCSC model 


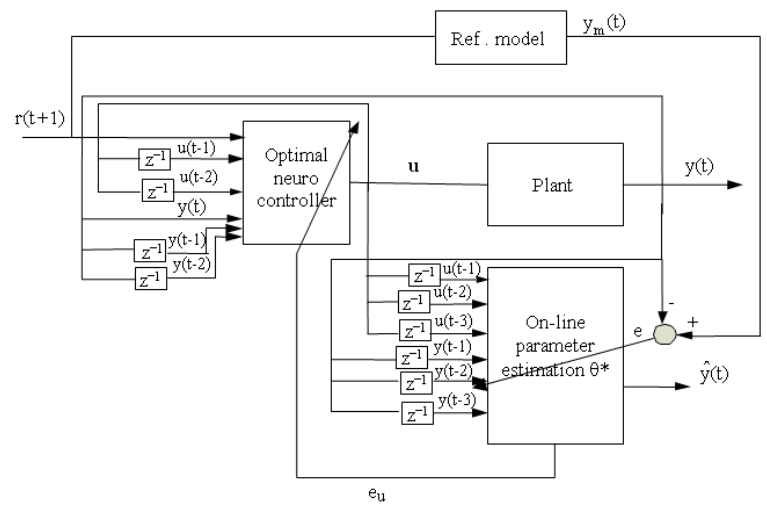

Fig. 2: Optimal neural network controller model

Neural network has been applied very successfully in the identification and control of dynamic systems. The universal approximation capabilities of the multilayer perceptron MLP make it a popular choice for modeling nonlinear systems and for implementing general-purpose nonlinear controller. The following describes the process of design of the neural network controller. There are typically two steps that involved when using neural network for control.

\section{System identification:}

Control design: In system identification stage, a model for the system that needs to be controlled should be developed. In control stage the developed model should be used in training the controller. This controller uses a neural network model to predict future plant responses to potential control signals. An optimization process then computes the control signal that optimizes the future plant performance ${ }^{[18]}$. The optimal neurocontroller design consists of two separate neural networks, namely the neuro-controller and the neuroidentifier. The structure for the training of the neuroidentifier and the neuro-controller is shown in Fig. 2. These two phases are carried out in series. The training algorithm and process of the neuro controller are described in detail in section below.

Neural network identifier: In order to provide a closer approximation to the dynamic behavior of the power system a Nonlinear Auto Regressive Moving Average (NARMA) model ${ }^{[17]}$ is employed in this study, which is identified by means of artificial neural networks. The neuro-identifier developed is a 3rd order model of the form:

$$
\mathrm{A}\left(\mathrm{z}^{-1}\right) \mathrm{y}(\mathrm{t})=\mathrm{B}\left(\mathrm{z}^{-1}\right) \mathrm{u}(\mathrm{t})+\zeta(\mathrm{t})
$$

where, $\mathrm{A}\left(\mathrm{z}^{-1}\right)$ and $\mathrm{B}\left(\mathrm{z}^{-1}\right)$ are polynomials in the backward shift operator $\mathrm{z}^{-1}$ and are defined as:

$$
\begin{aligned}
& \mathrm{A}\left(\mathrm{z}^{-1}\right)=1+\mathrm{a}_{1} \mathrm{z}^{-1}+\mathrm{a}_{2} \mathrm{z}^{-2}+\mathrm{a}_{3} \mathrm{z}^{-3} \\
& \mathrm{~B}\left(\mathrm{z}^{-1}\right)=\mathrm{b}_{1} \mathrm{z}^{-1}+\mathrm{b}_{2} \mathrm{z}^{-2}+\mathrm{b}_{3} \mathrm{z}^{-3}
\end{aligned}
$$

The variables $\mathrm{y}(\mathrm{t}), \mathrm{u}(\mathrm{t})$ and $\zeta(\mathrm{t})$ are the system output, system input and white noise respectively. For the purpose of identification, Eq. 7 can be written in the form of:

$$
y(t)=\theta^{T}(t) \varphi(t)+\zeta(t)
$$

Where:

$$
\begin{aligned}
& \theta(t)=\left[\begin{array}{llllll}
a_{1} & a_{2} & a_{3} & b_{1} & b_{2} & b_{3}
\end{array}\right] \\
& \varphi(t)=\left[\begin{array}{lll}
-y(t-1) & -y(t-2) & -y(t-3) \\
u(t-1) & u(t-2) & u(t-3)
\end{array}\right]^{T}
\end{aligned}
$$

where, $\theta(\mathrm{t})$ and $\varphi(\mathrm{t})$ are the parameter vector and the measurement variable vector, respectively. The typical structure of the MLP neural Network identifier is shown in Fig. 3. The network has six input neurons, five neurons in the hidden layer and a single layer of neuron in the output layer. MLP perceptron is used to track the dynamics of the system and modeled so that its weights have a one-to-one relationship with the ARMA parameters. The plant Identifier receives the plant input $u$ and plant output $y$ at one step of time $(\mathrm{t}-1)(\mathrm{t}-2)$ and $(\mathrm{t}-3)$, and give out the estimated output $\hat{y}$ through the ARMA method explained above. The parameters of the identifier are updated based on the error between the plant output y and its desired output $y_{m}$.

In this research the network is trained in advance with the nnarx function in the NNSYSID toolbox ${ }^{[19]}$. The variables defining the network includes input and two delayed inputs signals, output and two delayed output of the system as mention already together with initial weights of the network and then the number and types of neurons in hidden and output layer. Similar variable is specified as controller initials architecture.

Neuro-controller model: The neuro-controller is also a multi-layer feedforward network trained with Modified Recursive Prediction Error Algorithm (MRPE). The number of neurons in input, hidden and output layer is six, five and one respectively, each hidden neurons used tangent activation functions and a linear function in the output. The inputs to the Neuro-controller are actual plant output $y$ and its two previous values plus the two previous values of output of the Neuro-controller u together with reference signal. 


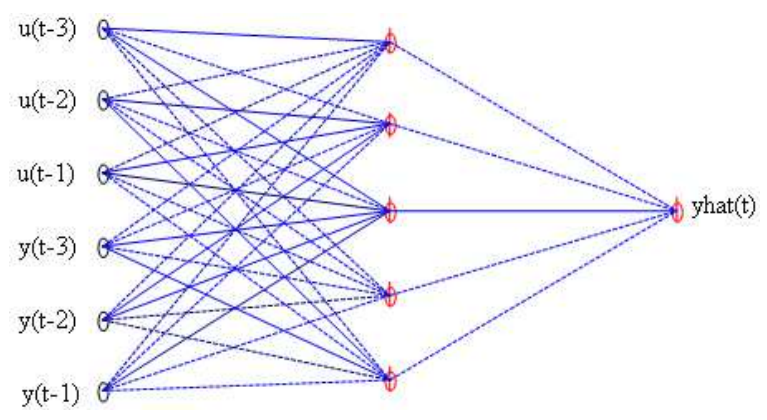

Fig. 3: Network of MLP model

Training algorithm: There are so many types of training algorithm of neural network most of them can be viewed as a straight forward application of optimization theory and statistical estimation. They include: Back propagation by gradient descent, Recursive Prediction Error algorithm (RPE), BFGS, CG. In this project a Modified Recursive Prediction Error Algorithm (MRPE) explained by ${ }^{[20]}$ is adapted here.

Modified recursive prediction error algorithm: Recursive Prediction Error algorithm (RPE) was originally derived by Ljung and Soderstrom ${ }^{[20,21]}$ and modified by ${ }^{[22]}$ to train MLP networks. RPE algorithm is a Gauss-Newton type algorithm that will generally give better performance than a steepest descent type algorithm such as back propagation algorithm. In the present study, the convergence rate of the RPE algorithm is further improved by using the optimized momentum and learning rate. The momentum and learning rate in this research are varied compared to the constant values in Chen et al. ${ }^{[22]}$. The RPE algorithm modified by Chen et al. ${ }^{[22]}$ minimizes the following cost function:

$$
\mathrm{V}_{\mathrm{N}}(\hat{\theta})=\frac{1}{2 \mathrm{~N}} \sum_{\mathrm{t}=1}^{\mathrm{N}} \varepsilon^{\mathrm{T}}(\mathrm{t}, \hat{\theta}) \Lambda^{-1} \varepsilon(\mathrm{t}, \hat{\theta})
$$

By updating the estimated parameter vector, (consists of w's and b's), recursively using GaussNewton algorithm: Where $\varepsilon(\mathrm{t})$ and $\Lambda$ are the prediction error and $\mathrm{m} \times \mathrm{m}$ symmetric positive definite matrix respectively and $\mathrm{m}$ is the number of output nodes. The weights (specified by the vector $\theta$, or alternatively by the matrices $\mathrm{w}$ and $\mathrm{W}$ ) are the adjustable parameters of the network and are determined through the process called training:

$$
\hat{\theta}(\mathrm{t})=\hat{\theta}(\mathrm{t}-1)+\mathrm{P}(\mathrm{t}) \Delta(\mathrm{t})
$$

and:

$$
\left.\Delta(\mathrm{t})=\alpha_{\mathrm{m}}(\mathrm{t}) \Delta(\mathrm{t}-1)+\alpha_{\mathrm{g}}(\mathrm{t}) \Psi_{\mathrm{u}}(\mathrm{t})\left(\mathrm{e}_{\mathrm{u}}(\mathrm{t})-\rho \mathrm{u}(\mathrm{t}-1)\right)\right)
$$

Where:

$\begin{array}{ll}\rho & =\begin{array}{l}\text { Penalty on squared differenced } \\ \text { controls }\end{array} \\ \alpha_{\mathrm{m}}(\mathrm{t}) \text { and } \alpha_{\mathrm{g}}(\mathrm{t})= & \begin{array}{l}\text { The momentum and learning rate } \\ \text { respectively }\end{array}\end{array}$

$\alpha_{\mathrm{m}}(\mathrm{t})$ and $\alpha_{\mathrm{g}}(\mathrm{t})$ can be arbitrarily assigned to some values between 0 and 1 and the typical value of are closed to 1 and 0 respectively. $\alpha_{\mathrm{m}}(\mathrm{t})$ and $\alpha_{\mathrm{g}}(\mathrm{t})$ used in this study are varied to further improve the convergence rate of the RPE algorithm according to:

$\alpha_{m}(t)=\alpha_{m}(t-1)+a$

and:

$\alpha_{g}(t)=\alpha_{m}(t)\left(1-\alpha_{m}(t)\right)$

where, a is a small constant (typically a $=0.01$ ); is normally initialized to $0 \leq \alpha_{\mathrm{m}}(0)<1$. $\psi(\mathrm{t})$ represents the gradient of the one step ahead predicted output with respect to the network parameters:

$\psi(\mathrm{t}, \theta)=\left[\frac{\mathrm{dy}(\mathrm{t}, \theta)}{\mathrm{d} \theta}\right]$

$\mathrm{P}(\mathrm{t})$ in Eq. 19 is updated recursively according to:

$\mathrm{P}(\mathrm{t})=\frac{\mathrm{d} \hat{\mathrm{y}}(\mathrm{t}, \theta)}{\mathrm{d} \theta}\left[\mathrm{P}(\mathrm{t}-1)-\frac{\mathrm{P}(\mathrm{t}-1) \psi(\mathrm{t}) \psi^{\mathrm{T}}(\mathrm{t}) \mathrm{P}(\mathrm{t}-1)}{\gamma}\right]$

$\gamma=\lambda(\mathrm{t}) \mathrm{I}+\psi^{\mathrm{T}}(\mathrm{t}) \mathrm{P}(\mathrm{t}-1) \psi(\mathrm{t})$

where, $\lambda(t)$ is the forgetting factor, $0<\lambda(t)<1$ and normally been updated using the following scheme:

$\lambda(t)=\lambda_{0} \lambda(t-1)+\left(1-\lambda_{0}\right)$

where, $\lambda_{0}$ and the initial forgetting factor $\lambda(0)$ are the design values. Initial value of covariance matrix $\mathrm{P}(\mathrm{t})$, $\mathrm{P}(0)$ is normally set to $\alpha \mathrm{I}$ where I is the identity matrix and $\alpha$ is a constant, typically between 10-10000. Small value of $\alpha$ will cause slow learning however too large may cause the estimated parameters do not converge properly $^{[21]}$. 
Training of the neural network identifier: The training process of the neuro-identifier is only trained around some stable operating point, it is necessary for it to be trained online to adapt to the cases when system states change. To obtain training data the power system model in consideration is simulated and the input/output data table is generated for different operating conditions. During this phase, the input and desired output of the neuro-identifier are $[\mathrm{y}(\mathrm{t}-1), \mathrm{y}(\mathrm{t}-2)$ $\mathrm{y}(\mathrm{t}-3), \mathrm{u}(\mathrm{t}-1) \mathrm{u}(\mathrm{t}-21), \mathrm{u}(\mathrm{t}-32)]$ and $\hat{\mathrm{y}}(\mathrm{t} 1)$ respectively, where $\hat{y}(t)$ is the most current system state.

Where:

$\mathrm{u}(\mathrm{t})=$ Input reference vector of the TCSC as $\left(\mathrm{P}_{\text {ref }}-\mathrm{P}_{\mathrm{L}}\right)$

$y(t)=$ Output vector for the system like speed of the generator and line active power

Training of the neural network controller: The training of the neural network controller takes place with the training of the neural network -identifier in cascade. During this period, the input to the Neurocontroller is $[\mathrm{y}(\mathrm{t}), \mathrm{y}(\mathrm{t}-1), \mathrm{y}(\mathrm{t}-2), \mathrm{u}(\mathrm{t}-1), \mathrm{u}(\mathrm{t}-2), \mathrm{r}(\mathrm{t}+1)]$ and the output is $\mathrm{u}$, which is then fed to the Neuroidentifier and evaluated against the desired output. The desired control signal is calculated through the neural network -identifier by comparing the output of the Neuro-identifier with the desired system response. The error signal in equation $e_{u}$ is used to update the weights of the Neuro-controller and the objective function used to train the optimal neural Network controller is given in Eq. 23:

$$
J(\theta)=\sum_{t}(r(t)-y(t))^{2}+\rho(u(t))^{2}, \quad \rho \geq 0
$$

The weights are updated as:

$$
\hat{\theta}(\mathrm{t})=\hat{\theta}(\mathrm{t}-1)+\mathrm{P}(\mathrm{t}) \psi_{\mathrm{u}}(\mathrm{t})\left(\mathrm{e}_{\mathrm{u}}(\mathrm{t})-\rho \mathrm{u}(\mathrm{t}-1)\right)
$$

Where:

$$
\begin{aligned}
\psi_{\mathrm{u}}(\mathrm{t}) \simeq \frac{\mathrm{du}(\mathrm{t}-1)}{\mathrm{d} \theta}= & \text { Gradient of the one step ahead input } \\
& \text { with respect to network parameters } \\
\mathrm{P}(\mathrm{t}) & \text { Covariance matrix determine from } \\
& \text { Eq. } 19 \\
\mathrm{e}_{\mathrm{u}}=\frac{\partial \mathrm{y}(\mathrm{t})}{\partial \mathrm{u}(\mathrm{t}-1)} \mathrm{e}(\mathrm{t})= & \text { Output error back propagated to the } \\
& \text { controller model } \\
\mathrm{\rho} & \begin{array}{l}
\text { Finality factor to penalize the } \\
\text { squared controls }
\end{array}
\end{aligned}
$$

The training algorithm implemented is a modified recursive Gauss-Newton algorithm based on Recursive
Prediction Error algorithm (RPE) mention in section above for minimizing the above objective function.

\section{RESULTS}

Simulations were performed in the Sirnulink environment of Matlab using a fixed step-size of $1 \mathrm{~m} \mathrm{sec}$ and ode 45 solvers. The results are separately presented for the two test cases that are 11 bus system and 145 bus systems.

\section{DISCUSSION}

Two area four machines with TCSC device: The First test system used for applying TCSC Neurocontroller is 11 bus systems, shown in Fig. 4. To evaluate the performance of designed TCSC Neurocontroller controller, the simulations are carried out under the following two conditions:

Case 1: For this case study, a three phase faults is applied at bus 8 for a $1 \mathrm{sec}$ and cleared after $1.05 \mathrm{sec}$ with a heavy load demand from area 2 of $650 \mathrm{MW}$ with all the tie-lines in place. Figure 5 presents the inter-area and local modes of oscillations for the treated TCSC devices. Figure 5 shows the superiority of TCSC Neuro-controller over its conventional counterpart.

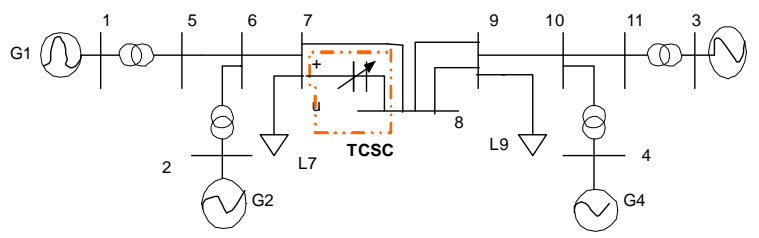

Fig. 4: Two area test system with TCSC neurocontroller

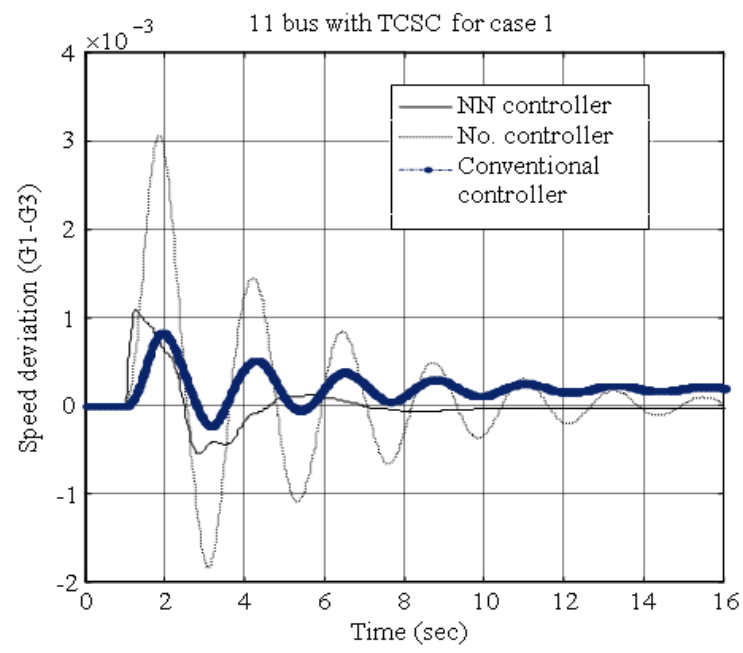

Fig. 5: Speed deviation of (G1-G3) for case 1 
Case 2: For this case study, a three phase faults is applied at bus 8 for a $1 \mathrm{sec}$ and cleared after $1.05 \mathrm{sec}$ with a normal load demand from area 2 of $400 \mathrm{MW}$ but with the tie-lines 7-8 outage. The interarea and local mode of oscillations for TCSC devices in the network is shown in Fig. 6. In this case, the responses of TCSC under Conventional control and Neuro-controller are presented. Figure 6 the superiority of Neuro-controller is clearly observed.

EEE 50 machines, 145 bus system with TCSC: The test system used for applying TCSC Neuro-controller is IEEE 145 bus system, shown in Fig. 7 to evaluate the performance of designed TCSC Neuro-controller controller, the simulations are carried out under the following two conditions:

Case 1: Three phase faults are applied at bus 6 on line between bus 6 and 12, followed by outage of the line 612. The fault is cleared $5.56 \mathrm{~m} \mathrm{sec}$ after the fault is applied

Case 2: Three phase fault is applied at bus 66 when one of the possible tie line between bus 65 and 66 is switched off. The fault is cleared $0.05 \mathrm{~m} \mathrm{sec}$ after.
Figure 8 and 9 shows the responses of power flow in controlled line were TCSC is connected and speed deviation of G128 with respect to G120 for case 1 respectively. From Fig. 8 and 9 the superiority of Neuro-controller is clearly observed. Similar results are obtained in Fig. 10 and 11 for case 2.

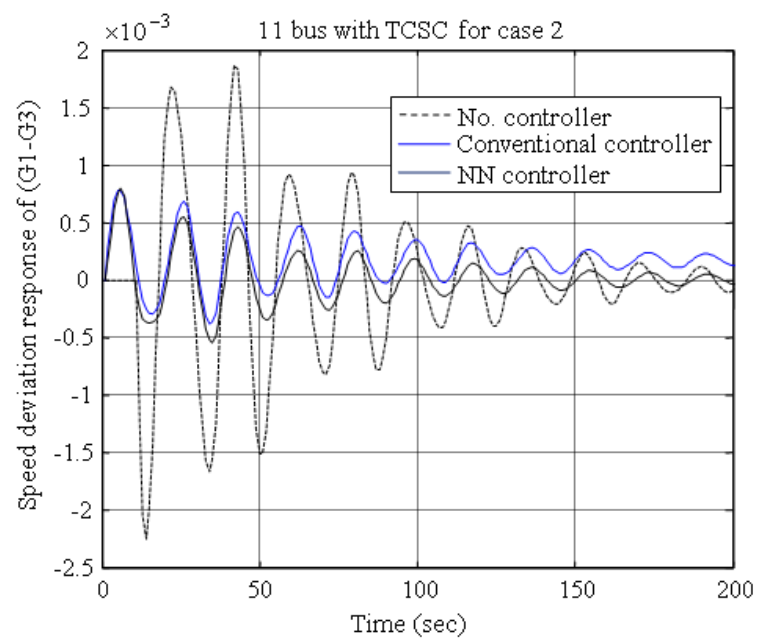

Fig. 6: Speed deviation of (G1-G3) for case 2

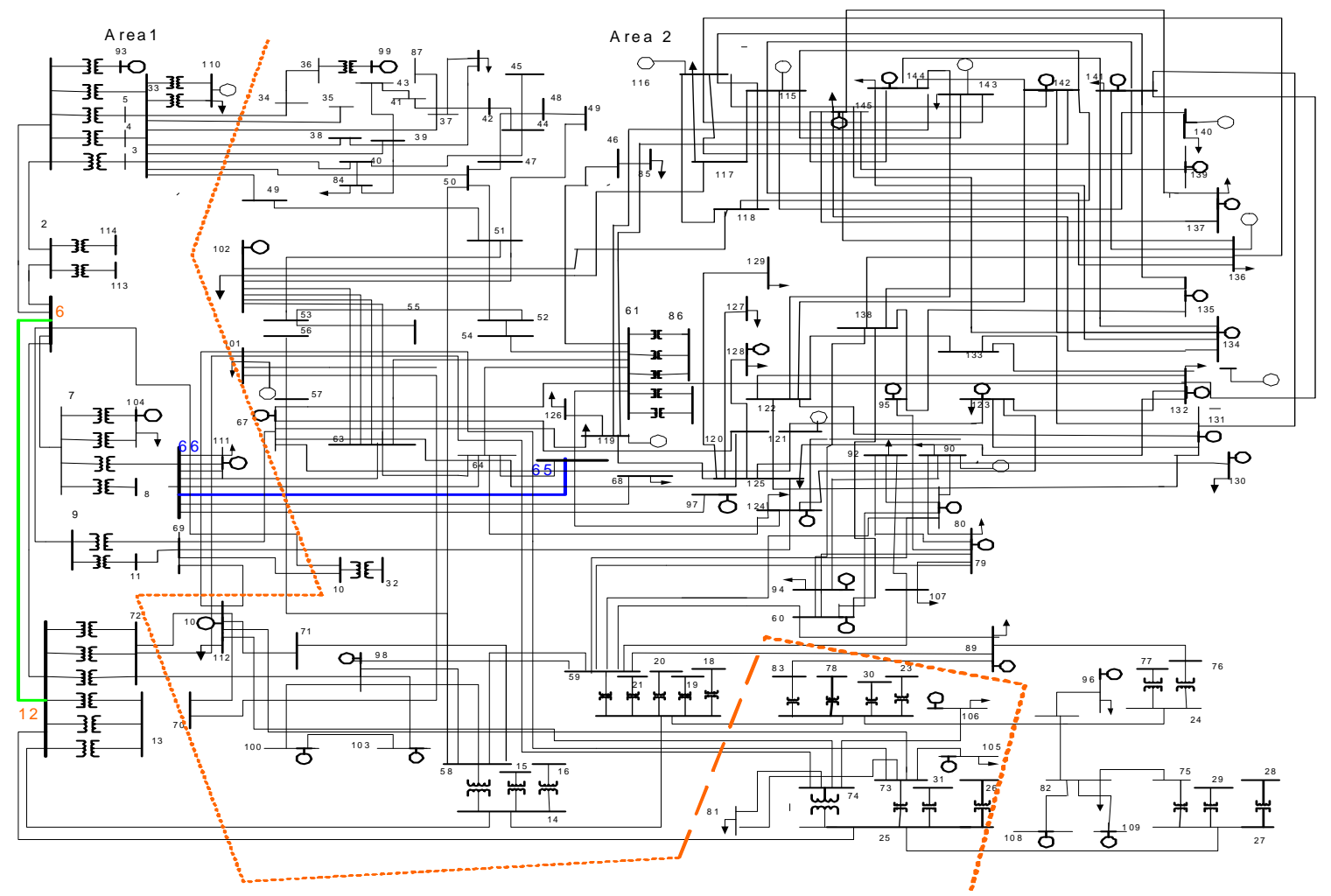

Fig. 7: IEEE 145 bus, 50 machine test systems 


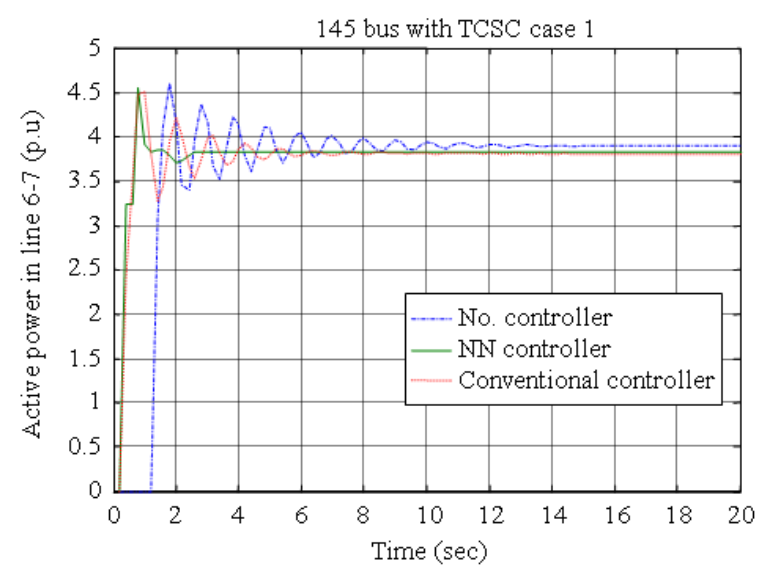

Fig. 8: Active powers for the TCSC placement in line 6-7 for case 1

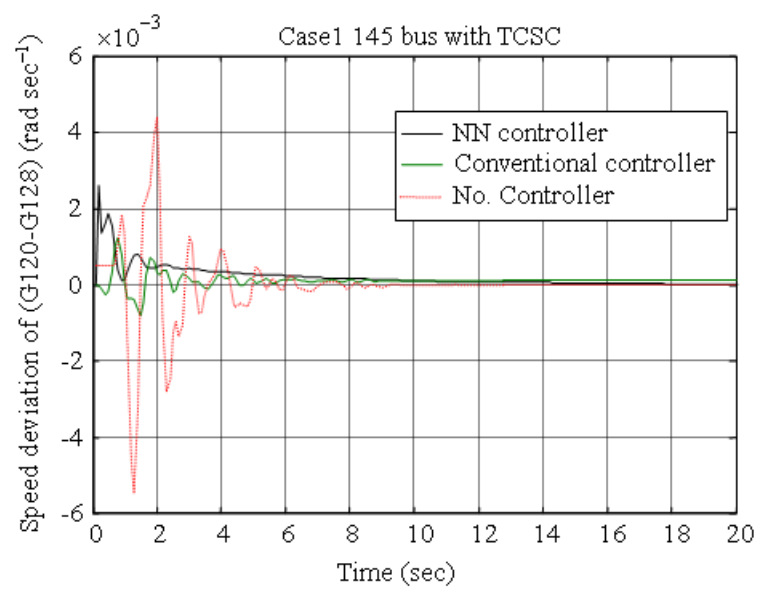

Fig. 9: Speed deviation of (G120-G128) for case 1

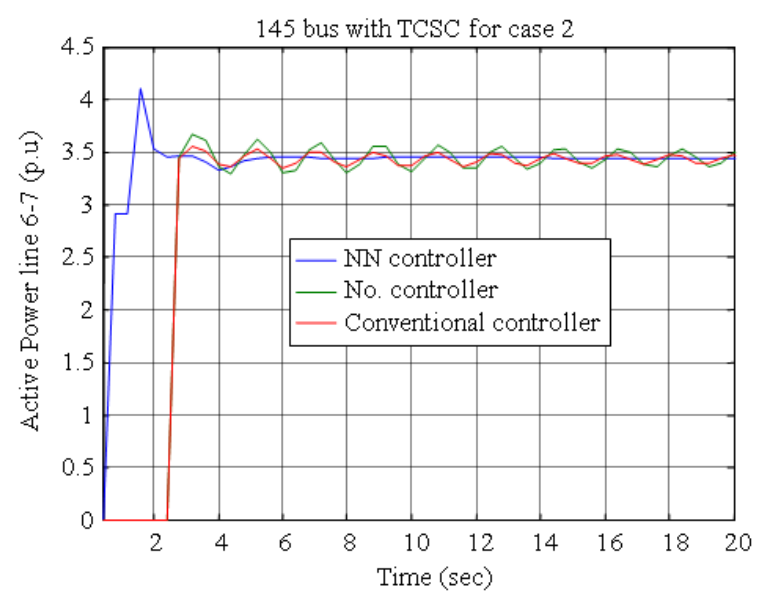

Fig. 10: Active powers for the TCSC placement in line 6-7 for case 2

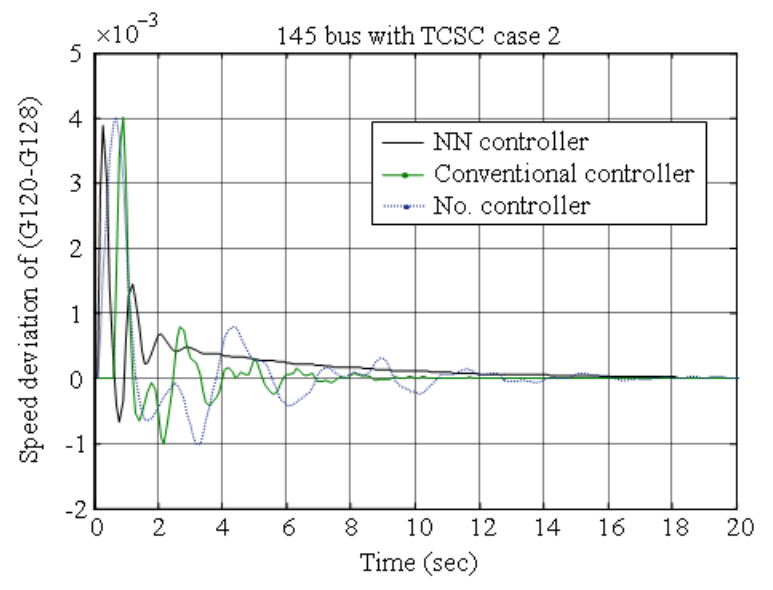

Fig. 11: Speed deviation of (G120-G128) for case 2

\section{CONCLUSION}

In this study, optimal Neuro-controller is proposed for damping oscillations and the effectiveness of the proposed control system is compared with Conventional controller under some disturbances. The controller is tested on a well known bench mark power system model proposed by Kundur called two area four machines system and a practical network of IEEE 145 bus system. From the results it can be concluded that the optimal Neuro-controller produces no steady state error and acceptable overshoot under some disturbances.

\section{ACKNOWLEDGMENT}

The researchers would like to express their appreciation to the University Technology Malaysia (UTM) and Ministry of Science Technology and Innovation (MOIST) for funding this research.

\section{REFERENCES}

1. Singh, S.N. and A.K. David, 2001. A new approach for placement of FACTS devices in open power market. IEEE Power Eng. Rev., 21: 58-60. http://ieeexplore.ieee.org/xpl/freeabs_all.jsp?arnum ber $=950290$

2. Kalyan Kumar, B., S.N. Singh and S.C. Srivastava, 2007. Placement of FACTS controllers using modal controllability indices to damp out power system oscillations. IET Generat. Transmiss. Distribut., 1: 209-217. DOI: 10.1049/ietgtd:20050529 
3. Bikash Pal and B. Chaudhuri, 2005. Robust Control in Power Systems. Springer, USA., ISBN10: 038725949X.

4. Magaji, N. and Mohd Wazir bin Mustafa, 2008. Application of SVC device for damping oscillations based on eigenvalue techniques. Int. J. Power Energy Artif. Intel., 1: 34-42. http://ijpeai.com/volume1.html

5. Leirbukt, A.B., J.H. Chow, J.J. Sanchez and E.V. Larsen, 1999. Damping control design based on timedomain identified models. IEEE Trans. Power Syst., 14: 172-178. DOI: 10.1109/59.744511

6. Rios-Patron, E. and R.D. Braatz, 1997. On the "identification and control of dynamical systems Using Neural Networks". IEEE Trans. Neural Networks, $\quad 8$ : 452 . $\quad$ DOI: 10.1109/TNN.1997.557703

7. Shamsollahi, P. and O.P. Malik, 1997. An adaptive power system stabilizer using on-line trained neural networks. IEEE Trans. Energy Convers., 12: 382-387. DOI: $10.1109 / 60.638951$

8. Wakshar Ray, Ganesh Kumar Venayagamoorthy, Balarko Chaudhuri and R. Majumder, 2008. Comparison of adaptive critic-based and classical wide-area controllers for power systems. IEEE Trans. Syst. Man Cybern. Part B: Cybern., 38: 1002-1007. DOI:

10.1109/TSMCB.2008.924141

9. Chandrakar, V.K. and A.G. Kothari, 2006. RBFN based Static Synchronous Series Compensator (SSSC) for Transient Stability improvement. IEEE ICARCV. DOI: 10.1109/ICARCV.2006.345227

10. Nguyen T.T. and R. Gianto, 2008. Neural networks for adaptive control coordination of PSSs and FACTS devices in multimachine power system. IET Generat. Transmiss. Distribut., 2: 355-372. DOI: $10.1049 /$ iet-gtd:20070125

Digital Object Identifier: 10.1049/iet-gtd:20070125

11. Wei Qiao, R. G. Harley and G.K. Venayagamoorthy, 2007. Neural-network-based intelligent control for improving dynamic performance of FACTS Devices. Proceeding of the 2007 IREP Symposium-Bulk Power System Dynamics and Control-VII, Revitalizing Operational Reliability, Aug. 19-24, IEEE Xplore Press, Charleston, South Carolina, USA., pp: 1-9. DOI: 10.1109/IREP.2007.4410550

12. Wei Qiao and Ronald G. Harley, 2007. Indirect adaptive external neuro-control for a series capacitive reactance compensator based on a voltage source PWM converter in damping power oscillations. IEEE Trans. Ind. Elect., 54: 77-85. DOI: 10.1109/TIE.2006.888759
13. Jeffrey, T., S. Pooner and K.M. Passino, 1996. Stable adaptive control using fuzzy system and neural networks. IEEE Trans. Fuzzy Syst., 4: 339-359. http://www.ece.osu.edu/ passino/kmp-pubs.html

14. Chao Lu, Jennie Si and Xiaorong Xie, 2008. Direct heuristic dynamic programming for damping oscillations in a large power system. IEEE Trans. Syst. Man Cybern. Part B: Cybern., 38: 1008-1013. DOI: 10.1109/TSMCB.2008.923157

15. Parka, J.W., G.R. Harleya and G.K. Venayagamoorthy, 2003. New internal optimal neurocontrol for a series FACTS device in a power transmission line. Adv. Neural Networks Res., 16: 881-890. DOI: 10.1016/S0893-6080(03)00121-7

16. P. K. Dash, S. Mishra and G. Panda., 2000. A radial basis function neural network controller for UPFC. IEEE Trans. Power Syst. 15: 1293-1299. DOI: $10.1109 / 59.898104$

17. Chetouani, Y., 2007. Using artificial neural networks for the modeling of a distillation column. International. J. Comput. Sci. Appli., 4: 119-133. http://www.tmrfindia.org/ijcsa/V4I310.pdf

18. Bahaa Ibraheem Kazem and N.F.H. Zangana, 2007. A neural network based real time controller for turning process. Jordan J. Mech. Ind. Eng., $1: 43-55$.

http://www.doaj.org/doaj?func=abstract\&id=283895

19. Nørgaard, M., 2004. Neural network based system identification toolbox Version 2. Technical University of Denmark, Department of Automation00-E-891.2000.

http://www.ac.tut.fi/aci/courses/76500/2004/harjoit us1/manual1.pdf

20. Mashor, M.Y., 2003. Modified recursive prediction error algorithm for training layered neural network. Int. J. Comput. Internet Manage., 11: 24-36. http://www.ijcim.th.org/past_editions/2003V11N2/ article03.pdf

21. Ljung, L. and T. Soderstrom, 1983. Theory and Practice of Recursive Identification. 4th Edn., MIT Press, Cambridge, ISBN: 10: 026212095X, pp: 529.

22. Chen, S., C.F.N. Cowan, S.A. Billings and P.M. Grant, 1990. A parallel recursive prediction error algorithm for training layered neural networks. Int. J. Control, 51: 1215-1228. DOI: $10.1080 / 00207179008934127$ 